\title{
Cartografia do cuidado na saúde da gestante
}

\section{Cartography of healthcare for pregnant women}

Raimunda Magalhães da Silva ${ }^{1}$

Milena Silva Costa ${ }^{2}$

Regina Yoshie Matsue ${ }^{1}$

Girliani Silva de Sousa ${ }^{1}$

Ana Maria Fontenelle Catrib ${ }^{1}$

Luiza Jane Eyre de Souza Vieira ${ }^{1}$

${ }^{1}$ Centro de Ciências da

Saúde/Mestrado em Saúde

Coletiva, Reitoria,

Universidade de Fortaleza.

Av. Washington Soares

1321, Edson Queiroz.

60811-905 Fortaleza CE.

rmsilva@unifor.br

${ }^{2}$ Universidade Federal de

Campina Grande
Abstract This work uses cartography as a method for mapping the trajectory of primary healthcare provided to pregnant women. The scope of the study comprises 9 Basic Healthcare Units located in the city of Juazeiro do Norte in the State of Ceará. In all, fifteen women in the 37th to 39th week of pregnancy were selected. Interviews were conducted with these women during the period from January to June 2010. The cartographic findings were depicted in stages in the flowchart, which exposed lacunas in prenatal healthcare, such as the low number of oncotic cytology exams conducted and the lack of educational counseling. Nevertheless, in the interviews, a significant number of pregnant women expressed satisfaction with the prenatal care provided. The good relationships developed between the healthcare professionals and the pregnant women were the main reason that led them to continue the treatment. This fact reinforces the importance of dialogue between these two actors for the success of prenatal healthcare.

Key words Pregnancy, Cartography, Comprehensive health and prenatal care
Resumo Utilizou-se a cartografia como método para mapear a trajetória do cuidado à gestante no serviço da atenção básica. O campo de estudo foram nove Unidades Básicas de Saúde do Município de Juazeiro do Norte (CE). Participaram 15 mulheres que estavam entre 37 e 39 semanas de gestação, com as quais foram realizadas entrevistas nos meses de janeiro a junho de 2010. Os achados da cartografia foram descritos em etapas no fluxograma e revelaram lacunas no serviço do prénatal, tais como o número reduzido da realização do exame da citologia oncótica e o déficit de atividades educativas. Observou-se, entretanto, certa resolubilidade na assistência à gestante, pois vários depoimentos demonstraram satisfação em relação ao serviço. A boa relação desenvolvida com o profissional foi o principal motivo que as levou a continuar o tratamento. Este fato reforça a importância do vínculo e do diálogo entre profissionais e gestantes para a adesão e sucesso do prénatal.

Palavras-Chave Gestação, Cartografia, Cuidado Integral, Pré-Natal 


\section{Introdução}

A gestação é um período no qual a mulher necessita de cuidados especiais pelo fato de vivenciar experiências singulares decorrentes de modificações fisiológicas e psicossociais. A equipe de saúde deve, então, acolher a gestante e desenvolver cuidados com o objetivo de prevenir riscos e promover uma gravidez saudável. A garantia do cuidado integral está fundamentada nas políticas de saúde da mulher $\left(\right.$ PHPN $^{1}$ e PNAISM $\left.{ }^{2}\right)$ e implementadas nas redes assistenciais de saúde. $\mathrm{Na}$ atenção pré-natal, o serviço de saúde deve fornecer as bases do cuidado, mediante o atendimento articulado, humanizado e com resolubilidade das ações ${ }^{3}$.

Nesta perspectiva, o cuidado na atenção prénatal deve incluir a qualidade da assistência; a atenção centrada na usuária e não na doença e o estabelecimento de uma relação dialógica entre os profissionais e as gestantes ${ }^{3}$. Sabe-se que o cuidado humanizado no pré-natal é o primeiro passo para um nascimento saudável, diminuição da morbimortalidade materna e fetal, aquisição de autonomia e vivência segura no ciclo gravídico ${ }^{4}$.

A maioria dos serviços de pré-natais do Brasil mostra alta cobertura, porém, poucos são classificados como adequados 5 . O cuidado na saúde da gestante encontra-se pautado nas queixas físicas e caracterizado pela fragmentação de suas ações, sendo insuficiente para promover a saúde da gestante ${ }^{6}$. Como resultado, a qualidade assistencial torna-se comprometida, possibilitando riscos de intercorrências no ciclo gravídico-puerperal.

Deve-se frisar que é necessário fundamentar as ações do cuidado à gestante na cultura do diálogo, pois a relação dialógica promove práticas mais humanas entre profissionais e usuárias e, consequentemente, resolutivas ${ }^{7}$. O cuidado deve ser um processo de trabalho em saúde, em que o vínculo entre os sujeitos e trabalhadores da saúde deve ocorrer de forma singular e afetiva, o que possibilita o acolhimento ${ }^{8}$.

Para que as ações em saúde da gestante contribuam no processo do cuidado, é importante que haja viabilização do acesso e inserção da mulher nas ações desenvolvidas no serviço de atenção básica. Com efeito, o cuidado no prénatal é um continuum no qual são desenvolvidas ações de saúde e, neste processo, é necessária uma visualização dos caminhos percorridos pela gestante no serviço de saúde. Essas trilhas inspiram a apresentar o processo do cuidar no for- mato da cartografia, pois esta revela muitos arranjos e sentidos para as práticas do cuidar ${ }^{9,10}$.

O método cartográfico propicia adentrar no complexo mundo da produção do cuidado em saúde, captando os ruídos dialógicos, a produção de afetos e as tecnologias de atenção à gestante ${ }^{10}$. Por conseguinte, a cartografia nos revela os processos de produção de subjetividades e dispositivos coletivos do cuidado.

Revendo as bases de dados Medline e Lilacs, notou-se a inexistência de artigos quando usados os descritores "gestante e cartografia do cuidado". Haja vista a lacuna de pesquisas e a relevância do tema, este trabalho visa a cartografar o cuidado à gestante no serviço de saúde da atenção básica em uma região do Nordeste do Brasil. Buscou-se identificar as relações estabelecidas entre equipe de saúde e usuárias, os nós críticos e os ruídos dialógicos apresentados no processo do pré-natal.

\section{Metodologia}

Optou-se pela pesquisa qualitativa, a qual permite a interpretação das particularidades dos comportamentos e das atitudes dos agentes sociais $^{11}$. A cartografia foi o método utilizado para mapear a trajetória da atenção à gestante, sendo um mapa relato, que opera na produção da realidade social e contribui para definir a modelagem dos serviços de saúde e o modo como se produz o cuidado ${ }^{10}$.

Para descrever a trajetória da gestante na busca e inserção no serviço de saúde e desenhar todas as etapas deste percurso, empregou-se o fluxograma descritor ${ }^{12}$. Este consiste em uma representação gráfica dos caminhos percorridos pela usuária, quando procura assistência prénatal. O fluxograma possibilita uma visão nítida sobre os fluxos em curso no momento da produção da assistência à saúde e permite a detecção de seus problemas.

Neste sentido, é fundamental que a elaboração do fluxograma seja coletiva; que haja uma acumulação de consciência da situação do serviço e apropriação dos processos vividos pelas usuárias. A elaboração coletiva, além de apresentar um produto rico de informações, permeado por múltiplos saberes, tem o efeito de formar uma opinião das usuárias em torno da realidade ${ }^{13}$.

O fluxograma da atenção à gestante foi representado por três símbolos: a elipse, que corresponde à entrada ou saída das usuárias dos serviços de saúde; o losango, indicando os mo- 
mentos de decisão para a continuidade da assistência; e o retângulo, significativo do momento de intervenção ${ }^{12}$.

O campo de estudo foram nove Unidades Básicas de Saúde (UBS) inseridas na zona urbana do Município de Juazeiro do Norte - Ceará, nos quais residia o maior número de gestantes. A escolha desta região do Nordeste brasileiro se justifica pelo fato de a Razão de Mortalidade Materna no Ceará (83 óbitos por 100.000) ser superior à realidade brasileira $(76,1 \text { óbitos por } 100.000)^{14}$.

A coleta de dados deu-se com suporte na formulação coletiva do fluxograma descritor, com a participação de 15 mulheres que estavam entre 37 e 39 semanas de gestação. Esse critério de seleção pautou-se no fato de a gestante estar no terceiro trimestre, com no mínimo de seis consultas de pré-natal realizadas. Assim, as gestantes supostamente teriam condições de descrever subjetivamente a trajetória vivenciada no serviço de saúde no seu ciclo gravídico.

A pesquisa de campo baseou-se em entrevista semiestruturada, a partir de um roteiro contendo dados sociodemográficos e obstétricos, bem como questões norteadoras sobre o acompanhamento às gestantes durante sua gravidez, orientações e cuidados realizados pela equipe de saúde.

As entrevistas ocorreram nos meses de janeiro a junho de 2010, no momento em que a gestante estava na sala de recepção da UBS. O tempo das entrevistas variou de 20 a 40 minutos, o que foi suficiente para que elas relatassem sua trajetória na atenção pré-natal.

Os achados da cartografia foram agrupados em etapas no fluxograma descritor: a entrada da gestante na Unidade Básica de Saúde; as consultas com médico e enfermeiro; e exames e encaminhamentos a outros profissionais e outros serviços de saúde. $\mathrm{O}$ estudo foi submetido à análise do Comitê de Ética da Universidade de Fortaleza e aprovado.

\section{Resultados e Discussão}

As 15 gestantes encontravam-se na faixa etária de 13 a 37 anos, 11 viviam com seus companheiros, três eram solteiras e uma separada. A renda familiar predominou entre um e dois salários mínimos, sendo que uma gestante não referiu renda, relatando ser dependente de ajuda de familiares. Quanto à profissão, oito trabalhavam em serviços variados, que não exigiam grau elevado de escolaridade, e sete eram donas de casa.
As gestantes deslocavam-se para a UBS utilizando ônibus, moto ou bicicleta, sendo que a maioria residia nas proximidades e caminhavam até o local. Este fato mostra que os domicílios das participantes, em sua maioria, estão inseridos no território da área adstrita das ESF. A proximidade foi o principal motivo para a escolha do serviço de saúde ${ }^{15}$.

Com relação ao histórico de saúde e obstétrico das gestantes, sete eram primíparas e, destas, uma com gestação de alto risco por ter apenas 13 anos de idade ${ }^{16}$. O número elevado de primíparas no estudo reforça a necessidade de uma atenção pré-natal pautada na integralidade, visto que nesta fase elas necessitam de orientação, acompanhamento e cuidado humanizado.

Quanto aos hábitos considerados não saudáveis ao binômio mãe-filho, quatro eram fumantes, sendo que uma delas informou haver parado de fumar na gestação atual. Vale ressaltar que o tabagismo durante a gestação aumenta em $70 \%$ o risco de a mulher ter abortamento espontâneo e $40 \%$ de parto pré-termo ${ }^{17}$. A gestante com a menor idade (13 anos) referiu ingerir bebidas alcoólicas no período gestacional.

As consultas de pré-natal variaram entre seis e 13, o que é considerado satisfatório pelo Ministério da Saúde ${ }^{16}$, que recomenda no mínimo seis consultas ${ }^{5}$.

\section{Descrição do Fluxograma}

A cartografia acompanhou a trajetória das mulheres no serviço de saúde, desde o início do pré-natal; acolhimento, consultas com médico e enfermeiro, exames de rotina, atividades educativas e encaminhamento para serviços de especialidades. O fluxograma da Figura 1 revelou as ofertas e o fluxo do cuidado recebido na atenção básica, acompanhando o processo gestacional e não visou à finalização do processo (o parto $)^{9}$.

As elipses representam a porta de entrada para realização do pré-natal na atenção básica, sendo definidas por três caminhos: seis gestantes entraram por demanda espontânea, três por referência do ACS e seis eram procedentes da rede privada.

A entrada na atenção básica dá início ao acolhimento e universaliza o acesso a todos os que necessitem. $\mathrm{O}$ acolhimento é fundamental para o bom funcionamento da rede de serviço de saúde. É o momento em que a equipe deve oferecer uma escuta qualificada à gestante ${ }^{18}$, interligando-a a um moto-contínuo de cuidado. Nessa ocasião, iniciam-se os diversos trânsitos da gestante 

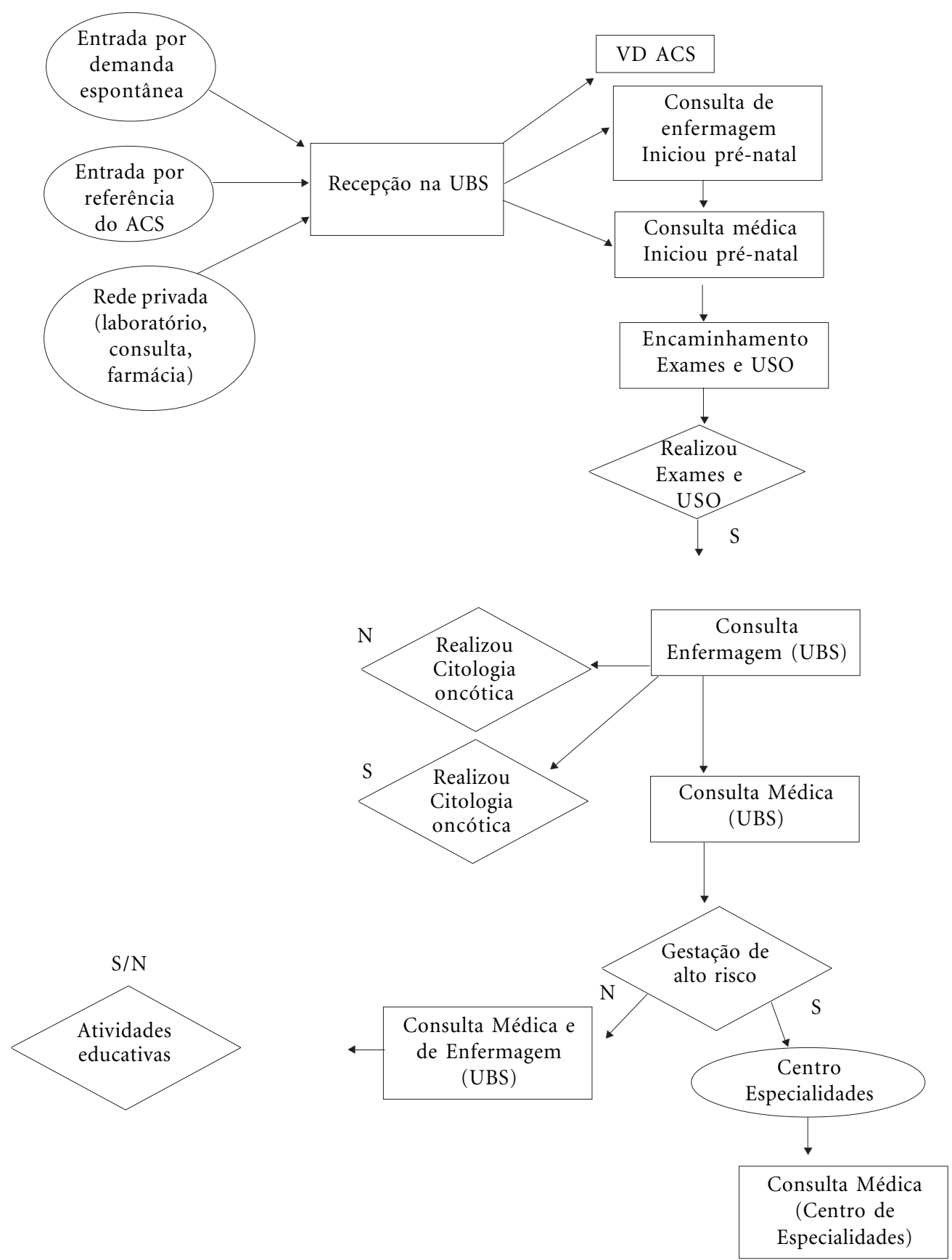

Figura 1. Fluxograma Descritor das Ações de Saúde Ofertadas às Gestantes

Fonte: Adaptação do Modelo de Fluxograma de Franco e Merhy (2004).

UBS - Unidade Básica de Saúde, VD - Visita Domiciliar, ACS - Agente Comunitário de Saúde, USO - Ultrassonografia, S - Sim, N-Não. 
pelo serviço, nos seus variados módulos de atenção, oportunidade em que a relação deve se estabelecer sob um firme vínculo e com diálogo entre a equipe de saúde e a mulher ${ }^{1,16}$.

A maioria das mulheres (dez) expressou satisfação no que concerne ao acolhimento e à atenção recebidas dos profissionais, enfatizando a importância do vínculo entre o profissional da UBS e a usuária.

Prefiro pegar ônibus e vim prá cá, o atendimento aqui é muito bom. Por causa dos meus problemas, a médica disse que minha gravidez era de risco, me mandou ir pro centro de especialidades, mesmo gostando do atendimento de lá continuo vindo pra médica daqui, porque ela é muito atenciosa comigo. A enfermeira também é bem boazinha!

Algumas mulheres (quatro), entretanto, prefeririam realizar o pré-natal pela rede privada, mas optaram pelo serviço de atenção básica por falta de recursos financeiros:

No meu primeiro parto sofri muito, não fui bem atendida no hospital do SUS. Quando minha menstruação atrasou fiz o teste no laboratório particular e comecei o pré-natal particular, fiz duas consultas. Mas pesou no orçamento lá de casa, então fiz aqui no posto mesmo.

Identificou-se também o fato de que uma gestante realizava pré-natal com o médico da ESF e, paralelamente, com o médico da rede privada:

Hoje faço o pré-natal aqui no posto e pago consulta particular, porque meu marido trabalha viajando e eu tive um problema de tireóide, tenho medo que aconteça qualquer coisa e aí não teria a quem recorrer. Acho bom ser acompanhada pelo médico daqui do posto e um particular.

Estes relatos mostraram preferência pela rede privada, o que ocorre em razão da crença de o atendimento da rede privada ser melhor do que o do sistema público de saúde. O SUS, na visão do usuário é considerado um serviço de saúde desorganizado, pautado em baixa qualidade, demandando longo tempo de espera e sem garantias de atendimento. Contrariamente, a rede privada é vista como um provedor de melhor qualidade, com atendimento pronto e confiável ${ }^{19}$.

Ante tal realidade, a Equipe de Saúde da Família deve explicar os objetivos e as vantagens da atenção básica. Precisa repassar confiança aos usuários, criar credibilidade nas ações desenvolvidas e promover a saúde da população, pautada no cuidado humanizado ${ }^{20}$.

$\mathrm{O}$ relato das mulheres revela elementos da relação destas com a equipe de saúde durante as consultas de pré-natal. Estas consistem na realização dos procedimentos técnicos, no levantamento das queixas, solicitação de exames de rotina do prénatal e orientações gerais sobre saúde e gravidez.

A maioria das mulheres (11) informou que médicos e enfermeiros atuavam em complementação das informações, apontando para uma razoável articulação entre a equipe.

Nas consultas, o médico diz que minha pressão está alta e tenho que fazer caminhada e comer mais frutas e verduras, sempre me dá muito conselho, me escuta, me explica as coisas, diz que eu tenho que gostar da criança, que eu não posso mais ta tomando remédio pra abortar. Já o enfermeiro, diz o que posso comer pra evitar anemia, tomar sulfato ferroso, não posso fazer relação sexual quando eu sentir dor no pé da barriga, não posso pegar em peso e nem fazer muito esforço. Ele examina e escuta o coração do bebê, mede o tamanho de minha barriga. Dou maior valor!

A consulta de pré-natal é o momento que enseja ao profissional de saúde elaborar o plano de ações específicas para cada mulher, de acordo com as necessidades físicas e psicossociais. A adesão e a satisfação das mulheres ao pré-natal estão relacionadas à qualidade da assistência prestada pelos serviços e profissionais de saúde. Estes devem esclarecer sobre os cuidados de todo o ciclo gravídico-puerperal ${ }^{16}$, utilizando uma linguagem popular que promova o diálogo, a humanização da relação e a colaboração da usuária para seguir as orientações ${ }^{7}$.

A efetivação dos exames laboratoriais também faz parte do cuidado na atenção básica. Constatou-se que todas as gestantes realizaram os exames de urina, séricos e de ultrassonografia obstétrica, recomendados para o pré-natal ${ }^{16}$. Os exames são fundamentais para detectar precocemente alguma complicação que as gestantes possam vir a apresentar durante o ciclo gravídico .

O exame de citologia oncótica, entretanto, foi realizado somente por cinco gestantes, sendo que as demais (dez) optaram por não fazê-lo.

Não fiz prevenção porque não tinha corrimento. Minha última prevenção foi em 2008. Mas depois senti dor no pé da barriga, o enfermeiro pediu para eu fazer a prevenção, mas não quis fazer.

Estes casos conduzem a que se questione sobre os motivos da não realização deste exame. Presume-se que o uso do instrumental médicohospitalar, a posição e o toque ginecológico, na maioria das vezes, por profissionais do sexo masculino, são os principais fatores geradores de dificuldades para a efetivação do exame ${ }^{21}$.

Em decorrência desta realidade, é necessário que o médico encontre um solo comum de conversação com a usuária, reconhecendo suas par- 
ticularidades, orientando-a, de modo que ela saiba encontrar o próprio caminho. A orientação do profissional implica também a permissão e não apenas a prescrição de regulamentos ou receitas. O diálogo é parte do tratamento e busca abolir a distância, promovendo a confiança e a adesão destas nas orientações dos profissionais ${ }^{7}$.

Ressalta-se neste estudo que a minoria (cinco) das gestantes que realizaram o exame de citologia oncótica o fizeram em virtude das informações repassadas pelos profissionais de saúde:

A enfermeira disse que era bom eu fazer a prevenção porque tava com inflamação, ai eu fiz com ela mesma.

A realização do exame colpocitológico é uma das ações preconizadas pela assistência pré-natal para o diagnóstico de infecções mais prevalentes do trato ginecológico ${ }^{1}$. Os profissionais de saúde deveriam compreender a subjetividade que perpassa a não realização do exame e buscar formas de comunicação que estimulem e convençam a usuária da importância desse procedimento ${ }^{6}$.

Nesta perspectiva, os profissionais de saúde devem inspirar-se na retórica do convencimento, na qual a verdadeira arte de curar, segundo Gadamer, deve primeiramente conhecer e considerar o ser humano na sua totalidade. Com este fim, há que buscar entender a essência multiforme da alma em que se quer implantar as convicções e a variedade dos discursos que se adaptam a cada estado da alma. A medicina é, então, comparada com a verdadeira retórica, que deve fazer atuar sobre a alma os discursos certos na forma certa $^{7}$. Isto envolve uma orientação contextualizada na realidade da gestante, que considere suas opiniões, levando-a a compreender a importância das considerações dos profissionais, livre de coerção ou prescrições previamente decididas, considerando a importância de sua participação no processo do pré-natal.

Quanto à visita do ACS, a minoria (quatro) das participantes se lembrou da atuação desse profissional e uma se queixou de não receber o acompanhamento periódico.

Só tenho queixa de uma coisa... é que minha agente de saúde não vai lá todo mês pra saber como eu estou. Ela só aparece mês sim e mês não.

Apesar desse depoimento, o estudo encontrou três gestantes que apresentaram confiança no ACS. Para uma delas a atuação desta profissional foi imprescindível para a realização do pré-natal.

Só comecei o pré-natal depois que eu já tava com uns quatro meses, como a minha mãe não podia saber, falei com minha agente de saúde e contei pra ela, mas pedi segredo. Pedi pra que ela ficasse com meu cartão (da gestante) porque tinha medo que minha mãe mexesse nas minhas coisas e descobrisse tudo.

Neste caso, o ACS foi o elo de comunicação entre a usuária e a equipe de Saúde da Família, encaminhando e viabilizando os cuidados e a atenção necessários ${ }^{22}$. As visitas domiciliares dos ACS devem refletir em melhor adesão da mulher ao serviço de saúde, maior facilidade do acolhimento e estabelecimento do vínculo com a equipe de saúde ${ }^{6}$.

Com relação às atividades educativas, somente uma gestante relatou haver participado:

Gostei das palestras que assisti aqui no posto sobre amamentação que uns estudantes estavam fazendo. Achei legal. Aprendi muita coisa.

A atenção pré-natal deve ultrapassar os ruídos, os bloqueios de comunicação e a descontinuidade do processo comunicativo, pautando suas ações no cuidado humanizado. O estudo revela, entretanto, que há uma fragmentação na linha de cuidado, pois as gestantes não estão participando de grupos de orientação para uma gravidez e um parto saudáveis.

Outros estudos ${ }^{20,23}$ demonstraram que os principais entraves para a não realização das orientações durante o pré-natal decorrem da falta de estrutura do serviço de saúde e da rapidez nas consultas de pré-natal. Este ensaio, entretanto, aponta o vínculo e o diálogo entre a equipe de saúde e a usuária como os principais elementos geradores de confiabilidade ${ }^{7}$, adesão e satisfação destas em relação os profissionais, suas orientações e o serviço de pré-natal.

\section{Considerações Finais}

A cartografia neste estudo possibilitou a análise do acompanhamento do pré-natal e a produção do cuidado às gestantes, com base no mapeamento das ações ofertadas pelos serviços de saúde do Município de Juazeiro do Norte-CE.

O fluxograma mostrou os caminhos percorridos pelas gestantes e, ao mesmo tempo, sugere pistas para se alcançar um cuidado mais humanizado e eficaz. Indicou ainda algumas lacunas e deficiências do serviço do pré-natal, como, por exemplo, número reduzido da efetivação do exame da citologia oncótica, refletindo a ausência de uma comunicação efetiva entre os profissionais e a usuária. Patenteou a quase inexistência de atividades educativas, comprometendo o cuidado, uma vez que esta fornece subsídios para ampliar o conhecimento e a autonomia das gestantes. 
Observou-se, entretanto, certa resolubilidade na assistência à gestante, pois uma grande parcela das mulheres demonstrou satisfação com as consultas realizadas pelos médicos e enfermeiros. Na opinião destas, o tratamento, o cuidado humanizado e a proximidade da moradia da USB foram os principais motivos que as levaram à adesão ao pré-natal. Este fato reforça a importância do vínculo e do diálogo com os profissionais como elementos essenciais para esta adesão e para a satisfação com o pré-natal.

Vale ressaltar a importância do diálogo como parte do tratamento e o significado da comunicação que se cria entre profissionais de saúde e usuárias. É necessário que os profissionais saibam ouvir, sobretudo, porque a usuária quer relatar suas experiências baseadas na sua visão de mundo. Ao permitir que a usuária manifeste opiniões e sentimentos, o profissional desenvolve uma base comum para estabelecer um vínculo e consolidar a colaboração no que concerne às suas orientações. Neste estudo, conclui-se que o diálogo é a condição primordial para estabelecer o cuidado humanizado, sendo necessário para que as barreiras de comunicação e os ruídos dialógicos entre profissionais e usuárias sejam superados.

\section{Colaboradores}

RM Silva, MS Costa, GS Sousa e RY Matsue trabalharam na concepção do projeto, coleta de dados, interpretação dos dados e redação do artigo. AMF Catrib e LJE Vieira participaram na revisão crítica e redação final do texto. 


\section{Referências}

1. Brasil. Ministério da Saúde (MS). Política nacional de atenção integral à saúde da mulher - Princípios e Diretrizes. Secretária de Atenção à Saúde, Departamento de Ações Programáticas Estratégicas. Brasília: Ministério da Saúde (MS); 2004.

2. Serruya SJ, Cecatti JG, Lago TG. O Programa de Humanização no pré-natal e nascimento do Ministério da saúde no Brasil: resultados iniciais. Cad Saude Publica 2004; 20(5):1281-1289.

3. Pinho IC, Siqueira JCBA, Pinho LMO. As percepções do enfermeiro acerca da integralidade da assistência. Rev Eletrônica de Enfermagem 2006; 8(1):4251.

4. Zampieri MFM, Erdmann AL. Cuidado humanizado no pré-natal: um olhar para além das divergências e convergências. Rev Bras Saúde Matern Infant 2010; 10(3):359-367.

5. Gonçalves CV, Cesar JA, Sassi RAM. Qualidade e equidade na assistência à gestante: um estudo de base populacional no Sul do Brasil. Cad Saude Publica 2009; 25(11):2507-2516.

6. Costa GD, Cotta RMM, Reis JR, Batista RS, Gomes AP, Franceschini SCC. Avaliação do cuidado à saúde da gestante no contexto do Programa Saúde da Família. Cien Saude Colet 2009; 14(Supl.1):1347-1357.

7. Gadamer HG. O caráter oculto da saúde. Petrópolis: Editora Vozes; 2006.

8. Merhy EE. Saúde: a cartografia do trabalho vivo. $3^{\mathrm{a}}$ ed. São Paulo: Editora Hucitec; 2002.

9. Passos E, Kastrup V, Escóssia L. Pistas do Método da Cartografia: pesquisa-intervenção e produção de subjetividade. Porto Alegre: Editora Sulina; 2010.

10. Franco TB, Andrade CS, Ferreira VSC, organizadores. A Produção Subjetiva do Cuidado: cartografias da estratégia saúde da família. São Paulo: Editora Hucitec; 2009.

11. Minayo MCS, Deslandes SF, Gomes R. Pesquisa Social: teoria, método e criatividade. Petrópolis: Editora Vozes; 2007.

12. Franco TB, Merhy EE. O Uso de Ferramentas Analisadoras para Apoio ao Planejamento dos Serviços de Saúde: o caso do serviço social do Hospital das Clínicas da UNICAMP (Campinas, SP). São Paulo: Hucitec; 2004.

13. Franco TB. Processos de trabalho e transição tecnológica na saúde [tese]. Campinas (SP): Unicamp; 2003.
14. Ceará. Secretaria Municipal de Saúde de Fortaleza [site na Internet]. [acessado 2010 mar 14]. Disponível em: http://www.saudefortaleza.ce.gov.br/sms_v2 /sms_pesquisaUS

15. Carvalho VCP, Araújo TVB. Adequação da assistência pré-natal em gestantes atendidas em dois hospitais de referência para gravidez de alto risco do Sistema Único de Saúde, na cidade de Recife, Estado de Pernambuco. Rev Bras Saúde Matern Infant 2007; 7(3):309-317.

16. Brasil. Ministério da Saúde (MS). Secretaria de Atenção à Saúde. Departamento de Ações Programáticas Estratégicas. Área Técnica de Saúde da Mulher. Pré-Natal e Puerpério: atenção qualificada e humanizada - manual técnico. Brasília: Ministério da Saúde (MS); 2006.

17. Iserhard ARM, Budó MLD, Neves ET, Badke MR. Práticas Culturais de Cuidados de Mulheres Mães de Recém Nascidos de Risco do Sul do Brasil. Escola Anna Nery Revista de Enfermagem 2009; 13(1):116122.

18. Schimith MD, Lima MADS. Acolhimento e vínculo em uma equipe do Programa Saúde da Família. Cad Saude Publica 2004; 20(6):1487-1494.

19. Bos AMG, Bos AJG. Determinantes na escolha entre atendimento de saúde privada e pública por idosos. Rev Saude Publica 2004; 38(1):113-120.

20. Costa AM. Integralidade na atenção e no cuidado a saúde. Saúde e Sociedade 2004; 13(3):5-15.

21. Davim RMB, Torres GV, Silva RAR, Silva DAR. Conhecimento de mulheres de uma unidade básica de saúde da cidade de Natal/RN sobre o exame de papanicolau. [site na Internet]. [acesso 2010 out 14]. Disponível em: http://www.scielo.br/pdf/ reeusp/v39n3/07.pdf

22. Figueiredo NMA. Ensinando a Cuidar em Saúde Pública. São Caetano do Sul: Ed. Difusão; 2005.

23. Rios CTF, Vieira NFC. Ações educativas no prénatal: reflexão sobre a consulta de enfermagem como um espaço para educação em saúde. Cien Saude Colet 2007; 12(2):1673-1681.

Apresentado em 05/09/2011

Aprovado em 16/10/2011

Versão final apresentada em 06/11/2011 